\title{
Riesgos laborales del personal técnico en inspecciones sanitarias de buques. Avanzando en conocimiento y organización
}

\section{Occupational Hazards of the Technical Staff Performing Ship Sanitation Inspec- tions. Building-up Knowledge and Organization Skills}

\section{M. ${ }^{a}$ Belén Robles García1, Paula María Marquéz Padorno, Rosemarie Neipp López, Mar Faraco Oñorbe 4}

1 Jefa de Servicio de Sanidad Exterior de Gijón. Doctora en Medicina y Cirugía. Médico especialista en Medicina Preventiva y Salud Pública y especialista en Pediatría y sus áreas específicas. Gijón. España.

2. Jefa de Servicio de Sanidad Exterior de Cartagena. Presidenta de la Asociación de Médicos de Sanidad Exterior. Médico especialista en Medicina Farmacéutica y Farmacología Clínica. Cartagena. España.

3. Jefa de Área de Control Sanitario. Subdirección General de Sanidad. Ministerio de Sanidad, Servicios Sociales e lgualdad. Médico especialista en Medicina Familiar y Comunitaria. Madrid. España.

4. Jefa de Servicio de Sanidad Exterior de Huelva. Secretaria y Relaciones Institucionales de la Asociación de Médicos de Sanidad Exterior. Médico especialista en Medicina de Familiar y Comunitaria. Huelva. España.

Recibido: 07-03-14

Aceptado: 09-05-14

\section{Correspondencia}

M. ${ }^{a}$ Belén Robles García

Claudio Alvargonzález n. ${ }^{\circ} 30$

33201 Gijón. España

Correo electrónico: mariabelen.robles@seap.minhap.es

Agradecimientos: a las personas que trabajan en Sanidad Exterior.

Resumen

Una de las funciones principales de Sanidad Exterior en España, es evitar la propagación internacional de enfermedades. Los equipos sanitarios son responsables de desarrollar las inspecciones de los buques que realizan desplazamientos internacionales, llevando a cabo actuaciones preventivas y de intervención. La seguridad laboral en este campo es necesaria para poder adoptar decisiones relativas al desempeño seguro y eficaz de estas tareas. El objetivo de este artículo es describir algunos de los elementos de riesgo a los que se expone el personal técnico durante todas las actividades de la inspección sanitaria de buques. Se necesita comenzar a dimensionar el problema, entre otros, implementando un sistema de formación en prevención de riesgos laborales que permita al personal técnico conocer y prevenir los nuevos retos que vayan surgiendo y los ya existentes.

Med Segur Trab (Internet) 2014; 60 (235) 304-312

Palabras clave: riesgo, lugar de trabajo, buques

Abstract

One of the main focuses of Port Health Authorities in Spain is to help prevent the international spread of diseases. Health teams are responsible for the development of health inspections on ships engaged in international travel, through the implementation of preventative and interventional practices. In this sense, job security is essential for making decisions regarding the safe and effective performance of these tasks. The objective of this paper is to describe some of the elements of risk to whom the technical staff will be exposed meanwhile the whole process and activities of the ship sanitary inspection. It is very important, even 
mandatory, to begin to assess the problems, through several activities which should include the implementation of a training system about occupational risk prevention to enable the staff with enough knowledge and skills to prevent any new emerging challenges that come, and indeed for those that already exist.

Med Segur Trab (Internet) 2014; 60 (235) 304-312

Key words: risk, workplace, ships 


\section{INTRODUCCIÓN}

Las enfermedades infecciosas se propagan geográficamente con mucha mayor rapidez y de manera más frecuente que en cualquier otro momento de la historia. La intervención adecuada y proporcionada para el control sanitario de estas situaciones se convierte en uno de los retos más importantes que tiene la Salud Pública en el siglo XXI. En los últimos años, la aparición de nuevas enfermedades infecciosas (Síndrome Respiratorio Agudo Severo, gripe pandémica, infección respiratoria por el nuevo coronavirus, etc.) y el aumento en la incidencia de otras que se creían controladas están provocando un impacto muy importante en la salud de los países afectados ${ }^{1,2}$. La actuación de Sanidad Exterior, como Organismo de la Administración General del Estado español, competente para evitar la propagación internacional de este tipo de enfermedades es fundamental, siendo los Controles Higiénico Sanitarios (CHS) en las fronteras una de las actividades principales ${ }^{3}$. Los equipos sanitarios de Sanidad Exterior son los responsables de desarrollar las inspecciones de los buques que realizan viajes internacionales, siendo la seguridad laboral en este campo una importante materia en revisión. Los trabajadores de cualquier empresa necesitan información y formación en este ámbito para poder adoptar decisiones diarias relativas al desempeño seguro y eficaz de sus tareas.

De forma general, se define riesgo como "combinación de la probabilidad y las consecuencias que se derivan de la materialización de un suceso peligroso especificado" ${ }^{4}$. En la práctica la Prevención de Riesgos Laborales (PRL) se basa en la seguridad relativa, es decir, en el control de los riesgos a niveles tolerables y adaptables.

Los máximos responsables orgánicos y funcionales de Sanidad Exterior deben demostrar su compromiso con el desarrollo e implementación de un sistema de gestión de riesgos en las inspecciones sanitarias de medios de transporte internacional, así como con la mejora continua de su efectividad y garantía del cumplimiento de las normas legales y reglamentos. Se necesita comenzar a dimensionar el problema y sus necesidades implementando un sistema de formación en PRL que permita a los inspectores ser flexibles a los nuevos retos que vayan surgiendo. El objetivo de esta revisión es describir algunos de los elementos de riesgo a los que se expone el personal técnico en la tarea de inspección sanitaria de buques. Los riesgos son impredecibles, todos no se pueden describir porque no se conocen, pero se intenta establecer una base de apoyo para encontrar soluciones y métodos más seguros de trabajo. Se concibe esta revisión además, como un instrumento informativo para quienes han de adoptar decisiones en esta materia con el objetivo de que sean establecidas medidas orientadas a prevenir los riesgos. La gestión de riesgos debería estar presente en las prácticas y en los procesos de la organización y en particular en los procesos de desarrollo de la política general de los mismos 5 .

\section{FUNCIONES DE SANIDAD EXTERIOR EN CONTROLES HIGIÉNICO SANITARIOS}

La función de inspección sanitaria de un buque consiste en certificar que las condiciones higiénicas del medio de transporte internacional son adecuadas, por lo general, es de carácter ordinario ${ }^{3}$. Sin embargo, el control de alertas sanitarias y el desembarco de enfermos o cadáveres son definidas como situaciones de riesgo, en los que la respuesta no admite demora. Por lo tanto, el personal técnico es responsable de todas las funciones en las que el objetivo es prevenir la propagación internacional de enfermedades. Para ello y, en función del tipo de inspección, emite los siguientes certificados: Declaración Marítima de Sanidad, Libre plática, Certificado de Sanidad a bordo (Exención o Control) y Abanderamiento. Todos los certificados se realizan dentro del marco del Reglamento Sanitario Internacional y de la Organización Mundial de la Salud ${ }^{6}$. 


\section{PREVENCIÓN DE RIESGOS LABORALES. NORMATIVA EN ESPAÑA}

Para desarrollar adecuadamente un plan de prevención, es imprescindible contar con unas reglas e instrucciones sobre los riesgos inherentes al trabajo. La relación de normas y recomendaciones existentes en materia de PRL en la inspección sanitaria de buques, debido quizás a sus especiales características, resulta confusa e inespecífica. La normativa internacional está regida por la Organización Marítima Internacional y por Directivas Europeas de Seguridad y Salud en el trabajo pero estas directrices presentan el problema de la no especificidad para estos trabajadores. El ordenamiento jurídico en España está conformado por Leyes, Decretos, Reglamentos y Ordenanzas, también de ámbito generalista. Se considera, al menos, en la normativa nacional:

Normas de base

- Constitución Española, de 27 de diciembre de $1978^{7}$.

- Ley 31/1995, de 8 de noviembre, de Prevención de Riesgos Laborales ${ }^{8}$.

- Ley 42/1997, de 14 de noviembre, de Inspección de Trabajo y Seguridad Social ${ }^{9}$.

Norma de desarrollo

- RD 39/1997, de 17 de enero, por el que se aprueba el Reglamento de los Servicios de Prevención ${ }^{10}$.

\section{LA SEGURIDAD Y LOS ACCIDENTES DE TRABAJO}

Los sistemas de seguridad en el tránsito por los puertos y buques son una de las mayores preocupaciones del personal técnico de Sanidad Exterior. La actividad marítima, en su conjunto, es una de las que presenta un mayor alto riesgo de accidentabilidad. La visita al buque se debe realizar acompañado por otro inspector/técnico y un tripulante. Por otra parte, sí existe un riesgo personal adicional la visita debe ser valorada por el Servicio de Prevención de Riesgos ${ }^{10}$.

Para minimizar el riesgo de las acciones inseguras, la empresa responsable del servicio, en este caso el Ministerio de Hacienda y Administraciones Públicas, debe garantizar que los inspectores y técnicos reciban una formación e información adecuadas sobre la salud y la seguridad durante toda la inspección.

Las condiciones seguras del buque y la gestión de cualquier emergencia es responsabilidad del Armador o del Capitán ${ }^{11}$.

\section{RIESGOS FíSICOS}

\subsection{Trayecto en coche. El Puerto y las instalaciones portuarias}

La normativa referente a la protección de los puertos y del transporte marítimo tiene por objeto, entre otros, establecer medidas orientadas a aumentar la protección de los puertos incluyendo amenaza de actos ilícitos deliberados ${ }^{12}$. Los inspectores deben conocer, en lo que les compete:

— "Planes de Protección del Puerto", "Plan de Protección de la Instalación Portuaria", "Plan de Emergencia Interior", "Plan Interior de Contingencias del Área de Influencia”, primeras actuaciones ante una emergencia y normas de acceso al recinto portuario.

- Normas de seguridad vial: hasta llegar el puerto se debe cumplir la normativa vial general de circulación por ciudad, en su caso, por carretera.

- Normas de la zona portuaria, entre otras, las siguientes: la velocidad máxima permitida de circulación es de $30 \mathrm{~km} /$ hora salvo señalización de lo contrario y la 
circulación de vehículos ligeros está prohibida, salvo autorización expresa. Además, se deben seguir las órdenes del Servicio de Policía Portuaria.

- Normas de prevención de riesgos laborales, entre otras, relacionadas con atropellos, golpes entre vehículos y/o máquinas, caídas personales, caídas por desplome de objetos, etc. ${ }^{8,11}$.

\subsection{Caída a distinto nivel y sobre el mismo nivel}

La consecuencia que puede derivarse del embarque y desembarque es, entre otras, la caída al mar. Para evitar este suceso se establecen las siguientes directrices ${ }^{11}$, que de no cumplirse, la visita no se realizará:

- El acceso debe efectuarse por medio de una escala real o de una pasarela de atraque, que debe mantenerse durante toda la visita, y nunca mediante un buque que este abarloado. No se debe acceder si la escalera no dispone de barandillas, red de protección e iluminación adecuada.

- Todos los medios de acceso deben estar libres de grasa, nieve, hielo o toda sustancia que pueda causar un deslizamiento y, ninguna carga suspendida debe pasar por encima.

- Durante toda la inspección pero especialmente durante el embarco y desembarco, se debe garantizar la estabilidad del buque.

El tránsito por cubierta debe ser seguro. Se debe seguir para acceder a los compartimentos interiores las líneas amarillas pintadas sobre el suelo ${ }^{11,13,14}$. Además, se debe permanecer alerta ya que las condiciones varían constantemente: suelos en mal estado, sustancias derramadas, apilamientos de material, tapas de escotillas abiertas, grúas con pesos suspendidos, cables en tracción, chigres en marcha, estibas, golpes de mar, viento, etc.

\subsection{Condiciones meteorológicas}

Una parte del trabajo se realiza al aire libre, por lo que sí existen condiciones meteorológicas adversas por si solas o combinadas con otros factores, como los años y la vida profesional del buque, se debe retrasar la inspección. Se deben utilizar trajes, botas con suela de agarre, cazadoras, de alta visibilidad, etc.

\subsection{Inspección de los compartimentos interiores}

En todas las operaciones de desplazamiento e inspección por los diferentes espacios interiores se han de seguir igualmente procedimientos de trabajo seguros ${ }^{11,13}$.

De manera general, el orden y la limpieza son importantes para prevenir no sólo accidentes por caídas sino otras situaciones potencialmente peligrosas.

Además, la movilidad dentro del barco es reducida, los pasillos son estrechos, las puertas son difíciles de abrir y las escaleras estrechas y pendientes. Por ello, las barandillas, escaleras, corredores, pasillos, accesos y puertas deben permitir el movimiento, evitando atrapamientos y golpes ${ }^{11,13}$.

El acceso a las gambuzas se debe hacer con garantías de seguridad extremas. La iluminación y ventilación debe ser adecuada, el suelo debe estar recubierto con una capa antideslizante y no debe existir agua estancada. Aunque extremadamente rara la posibilidad de que se cierren las puertas durante la visita, debe considerarse. Por ello, las puertas de las gambuzas, cámaras frigoríficas, etc. deberían estar provistas de un sujetador suficientemente resistente, un dispositivo que permita abrirlas desde el interior y un accionador del sistema de alarma interior y exterior ${ }^{11}$ 


\subsection{Otros riesgos}

Los compartimentos del buque deben estar debidamente ventilados para que exista, de manera constante, aire fresco y se impida la condensación. Se deberán evitar las temperaturas extremas y sus cambios bruscos, las humedades, las corrientes de aire y los olores desagradables ${ }^{15}$.

En relación a los incendios y explosiones, en un alto porcentaje de casos, son debidos a intervención humana, siendo la asfixia por humo la mayor responsable de las muertes. Los dispositivos de lucha contra incendios deberán encontrarse siempre en su lugar y mantenerse en perfecto estado de funcionamiento ${ }^{11,13,16}$. Los inspectores deberán conocer su emplazamiento y como utilizarlos, además de saber exactamente qué hacer en caso de siniestro14. El incendio tiene mayor riesgo de producirse durante la visita de la sala de máquinas y cocinas. Si se realiza inspección del incinerador, el área ha de estar limpia y la apertura de las puertas no está autorizada. En todo el buque los desechos, trapos y demás desperdicios, deberían eliminarse con arreglo a lo dispuesto por la legislación del Convenio Internacional para prevenir la contaminación por los Buques (MARPOL) ${ }^{17}$. Además, está terminantemente prohibido fumar en todos los espacios interiores.

El inspector no debe realizar ningún levantamiento, colocación, empuje o tracción de objetos para acceder a un compartimento, o cualquier actividad que por sus condiciones ergonómicas inadecuadas entrañe riesgos.

El grado de seguridad con el que se ejecuta el trabajo depende de la capacidad visual y ésta depende, a su vez, de la cantidad y calidad de la iluminación ${ }^{11,13}$. Un cambio brusco de luz o una iluminación inadecuada durante la inspección puede originar accidentes, fatiga ocular, cansancio, dolor de cabeza y estrés.

El origen de los accidentes de origen eléctrico está relacionado con los variados y sofisticados aparatos que se utilizan pero, sobre todo, con que la mayor parte del buque está construido con metales conductores de electricidad ${ }^{13,16}$.

La lesividad del ruido no depende exclusivamente de sus propias características (intensidad y cadencia), sino también del lugar de exposición y de factores personales del sujeto expuesto. El acceso a la sala de máquinas debe ser con cascos de protección auditiva, o al menos con tapones auditivos ${ }^{13,15}$.

Las radiaciones ionizantes y no ionizantes teóricamente pueden producir efectos sobre la salud de los inspectores, pero en la práctica el riesgo es insignificante.

\section{RIESGOS QUÍMICOS}

Es frecuente que mientras el buque está atracado en puerto, se estén llevando a cabo obras que puedan desprender polvo originado, entre otros, por la pulverización de pinturas, emisiones de trabajos de soldadura, etc. Además, el tipo de carga del buque puede ser también polvo o compuestos químicos. Todas estas sustancias pueden ocasionar, incluso por exposiciones de corto tiempo, alteraciones de la respiración, irritaciones, sensibilizaciones alérgicas, asma, conjuntivitis y daños sobre diversos órganos. Las recomendaciones de prevención para los inspectores se basan en utilizar los Equipos de Protección Individual (EPI) incluyendo, protección ocular, guantes tipo látex o nitrilo, mascarillas, etc. ${ }^{18-20}$.

Los inspectores no deben utilizar productos químicos para lavarse las manos procedentes de recipientes sin etiqueta, ni manipular desechos químicos que puedan encontrar durante la visita al buque. 


\section{RIESGOS BIOLÓGICOS}

El caso primario o secundario de muchas enfermedades, con alta letalidad, puede aparecer en un tripulante o pasajero de un buque, teniendo que tomar decisiones en las que la urgencia no permite demorar la respuesta. El desembarco de cadáveres también conlleva alto riesgo biológico. En todas las visitas de buques se debería llevar el EPI, material médico y el sistema de comunicación necesario para todas las actuaciones ${ }^{21}$. El personal técnico debe estar específicamente formado en este tipo de riesgos?.

\subsection{Enfermedades víricas}

Durante toda la visita al buque, pero especialmente en la inspección de las instalaciones médicas y del área de procesamiento de residuos, se debe evitar contacto con residuos punzocortantes (agujas, cuchillas) que no estén almacenados en un contenedor adecuado. El objetivo es evitar, entre otros, el contagio de hepatitis B, C y del Virus de la Inmunodeficiencia Humana21,22. Las cortaduras superficiales y las raspaduras deben ser tratadas inmediatamente contactando además con el Servicio de Prevención correspondiente.

La infección por virus Norwalk es la más frecuente en los buques de pasaje (Subdirección General de Sanidad Exterior. Ministerio de Sanidad Servicios Sociales e Igualdad. Manual de actuación ante alertas sanitarias en fronteras. Documento no publicado). La vía de transmisión es fecal-oral o por fómites (contaminación cruzada). Se recomiendan las medidas generales para lograr la interrupción de la cadena de transmisión.

Las infecciones respiratorias (varicela, sarampión, parotiditis, gripe, coronavirus, Síndrome Respiratorio Agudo Severo, etc.) son también enfermedades virales que se podrían transmitir durante la inspección1,2. El mecanismo de contagio es por contacto directo con las secreciones nasofaríngeas.

Las fiebres hemorrágicas, enfermedades infecciosas con alta letalidad aunque extremadamente raras, constituyen un riesgo potencial para los inspectores ${ }^{23}$. Todos los virus responsables están restringidos geográficamente a zonas en las que habitan las especies que intervienen en su ciclo natural (África, algunas áreas de Sudamérica, del Este de Europa, del Oriente Medio y del Lejano Oriente), sin embargo podrían asentarse en Europa meridional, donde ya existen vectores y reservorios adecuados para su mantenimiento $^{23}$. Una persona en periodo de incubación o enferma, en un medio de transporte internacional, podría ser el primer foco de transmisión secundaria. El personal que intervenga en el diagnóstico y transporte del paciente con sospecha de fiebre hemorrágica debe estar adecuadamente formado y protegido ${ }^{8}$.

\subsection{Enfermedades bacterianas}

La transmisión de infecciones bacterianas a los inspectores es insignificante pero también ha de considerarse. La mayoría de los tipos de gastroenteritis transmitidas por agua y alimentos en la población general, ocurren también en los buques siendo la salmonelosis la enfermedad bacteriana mejor documentada (Subdirección General de Sanidad Exterior. Ministerio de Sanidad Servicios Sociales e Igualdad. Manual de actuación ante alertas sanitarias en fronteras. Documento no publicado). Se recomiendan las medidas generales para lograr la interrupción de la cadena de transmisión.

La enfermedad de los legionarios, fiebre tifoidea, tuberculosis, etc. son enfermedades infecciosas bacterianas documentadas en los cruceros de pasaje y buques mercantes.

\subsection{Mordeduras}

En las regiones cálidas y templadas, las mordeduras de serpiente y de animales venenosos se mencionan en la normativa laboral como riesgos biológicos ${ }^{24}$. En la inspección de cocinas, áreas de almacenamiento de residuos, gambuzas y bodegas la mordedura por animales (ratas, culebras, arañas, escorpiones etc.) es un ejemplo de 
riesgo profesional difícilmente prevenible y no regulado. El personal debe estar adecuadamente protegido, contactando, en su caso, con un Servicio de Urgencias.

\section{RIESGOS PSÍQUICOS. EL ESTRÉS LABORAL}

Para cumplir dignamente su cometido, el inspector ha de reunir tres condiciones, las que pertenecen propiamente a la personalidad, las adscritas a la formación científica y las incluidas en la inclinación vocacional. Cada visita a un buque es una situación desconocida existiendo múltiples oportunidades que pueden mermar, desafiar o superar la actitud del equipo, produciendo fatiga, descenso de la concentración y ansiedad. Resulta fundamental facilitar una formación adecuada que permita el ajuste emocional necesario para superar todas estas potenciales situaciones ${ }^{9}$.

\section{EL OBJETIVO FINAL: LA GESTIÓN DE RIESGOS}

La inspección sanitaria de buques es una función poco conocida y estudiada por los Servicios de Prevención, servicios que son, sin embargo, los responsables de identificar situaciones de riesgo y prevenirlas. Los índices de siniestralidad deben asimismo incorporarse en la métrica de los Servicios de Prevención cuyo objetivo, compartido con otras muchas actividades, debe ser el de número de accidentes igual cero.

Es necesario implantar en España un sistema para la gestión de riesgos, en la función de CHS de Sanidad Exterior, que permita identificarlos para reducirlos o minimizarlos. Una vez implantado, se debe mantener y evaluar de forma continua, desarrollando acciones de mejora dónde se detecten deficiencias.

\section{REFERENCIAS BIBLIOGRÁFÍCAS}

1. Centers for Disease Control and Prevention. Update: outbreak of severe acute respiratory syndrome-worldwide, 2003. Morb Mortal Wkly Rep 2003;52(13):269-72.

2. Red Nacional de Vigilancia Epidemiológica. Centro Nacional de Epidemiología. Instituto de Salud Carlos III. Protocolo para la vigilancia y control del Síndrome Respiratorio Agudo Severo (SRAS). Ultimo acceso: 5/03/2014. Disponible en: http://www.isciii.es/ISCIII/es/contenidos/fd-servicios-cientifico-tecnicos/ fd-vigilancias-alertas/vigilancia-sindrome.pdf

3. Real Decreto 1418/1986, de 13 de junio, sobre funciones del Ministerio de Sanidad y Consumo en materia de sanidad exterior. BOE núm. 164, de 10 de julio de 1986, páginas. 25037-25039.

4. Asociación Española de Normalización y Certificación. Sistemas de gestión. Guía para la integración de los sistemas de gestión. Norma UNE 66177, de Junio de 2005, páginas 1-25.

5. Asociación Española de Normalización y Certificación. Sistemas de gestión de la calidad. Fundamentos y vocabulario. Norma UNE -EN ISO 9000, de Noviembre de 2005, páginas 1-35.

6. Organización Mundial de la Salud. Reglamento Sanitario Internacional. Ultimo acceso: 05/03/2014. Disponible en: http://www.who.int/ihr/es/

7. Constitución Española. BOE núm. 311, de 29 de diciembre de 1978, páginas 29313-29424

8. Ley 31/1995, de 8 de noviembre, de prevención de Riesgos Laborales. BOE núm. 269, de 10 de noviembre de 1995, páginas 32590-32611.

9. Ley $42 / 1997$, de 14 de noviembre, Ordenadora de la Inspección de Trabajo y Seguridad Social. BOE núm. 274, de 15 de noviembre de 1997, páginas 33539-33548.

10. Real Decreto 39/1997, de 17 de enero, por el que se aprueba el Reglamento de los Servicios de Prevención. BOE núm. 27, de 31 de Enero de 1997, páginas 3031-3034.

11. Oficina Internacional de Trabajo. Prevención de accidentes a bordo en los buques en el mar y en los puertos. Ultimo acceso: 5/03/2014. Disponible en: http://www.ilo.org/wcmsp5/groups/public/@ed protect/@protrav/@safework/documents/normativeinstrument/wcms_112632.pdf 
12. Ley 33/2010, de 5 de agosto, de modificación de la Ley 48/2003, de 26 de noviembre, de régimen económico y de prestación de servicios en los puertos de interés general. BOE núm. 191, de 7 de agosto de 2010, páginas 68986-69113.

13. Real Decreto 486/1997, de 14 de abril, por el que se establecen las disposiciones mínimas de seguridad y salud en los lugares de trabajo. BOE núm. 97, de 23 de abril de 1997, páginas 12918-12926.

14. Real Decreto 485/1997, de 14 de abril, sobre disposiciones mínimas en materia de señalización de seguridad y salud en el trabajo. BOE núm. 97, de 23 de abril de 1997, páginas 12911-12918.

15. Organización Internacional del Trabajo. Convenio sobre la protección de los trabajadores contra los riesgos profesionales debidos a la contaminación del aire, el ruido y las vibraciones en el lugar de trabajo. Último acceso: 5/03/2014. Disponible en: http://www.ilo.org/dyn/normlex/ es/f?p=NORMLEXPUB:12100:0::NO::P12100_ILO_CODE:C148

16. DIRECTIVA 1999/92/CE, del Parlamento Europeo y del Consejo, de 16 de diciembre de 1999, relativa a las disposiciones mínimas para la mejora de la protección de la salud y la seguridad de los trabajadores expuestos a los riesgos derivados de atmósferas explosivas. Diario Oficial de la Unión Europea L 23, 28 de enero de 2000, páginas 1-14.

17. Organización Marítima Internacional. Convenio Internacional de 1973 para Prevenir la Contaminación por los Buques, modificado por su Protocolo de 1978. Último acceso:5/03/2014. Disponible en: http:// www.fomento.es/NR/rdonlyres/2A2D8B5F-EEAE-4AED-BC7D-115A2000BF20/2154/marpol articulos. pdf

18. Organización Internacional del Trabajo. Exposición profesional a substancias nocivas en suspensión en el aire (Ginebra, 1980). Ultimo acceso:5/03/2014 . Disponible en: http://www.ilo.org/wcmsp5/groups/ public/ed_protect/protrav/safework/documents/normativeinstrument/wcms_112662.pdf

19. Real Decreto $374 / 2001$, de 6 de abril, sobre la protección de la salud y seguridad de los trabajadores contra los riesgos relacionados con los agentes químicos durante el trabajo. BOE núm. 104, de 1 de mayo de 2001, páginas 15893-15899.

20. Real Decreto $773 / 1997$, de 30 de mayo, sobre disposiciones mínimas de seguridad y salud relativas a la utilización por los trabajadores de equipos de protección individual. BOE núm. 140, de 12 de junio de 1997, páginas 18000-18017.

21. Kuhar DT, Henderson DK, Struble KA, et al. Updated US Public Health Service guidelines for the management of occupational exposures to human immunodeficiency virus and recommendations for postexposure prophylaxis. Infect Control Hosp Epidemiol 2013;34(9):875-892.

22. Instituto de Salud Carlos III, Escuela Nacional de Medicina del Trabajo y Asociación Nacional de Medicina del Trabajo en el Ámbito Sanitario. Guía de actuación ante exposición ocupacional a agentes biológicos de transmisión sanguínea. Último acceso: 5/03/2014. Disponible en: http://gesdoc.isciii.es/gesdoccontrol ler?action=download\&id=29/05/2012-d0f0d 27170 .

23. Instituto de Salud Carlos III. Manejo y control de las fiebres hemorrágicas virales. Ultimo acceso: 5/03/2014. Disponible en: http://aevi.isciii.es/Documentos/ManejoControl/Manual.PDF

24. Asamblea Nacional, Panamá. Anteproyecto de ley número 52, del 8 de septiembre del 2012, mediante el cual se regula la provisión de suero antiofídico en los centros de salud y otras localidades de la República de Panamá. Ultimo acceso:5/03/2014. Disponible en: http://www.asamblea.gob.pa/apps/seg_legis/PDF_ SEG/PDF SEG 2010/PDF SEG 2012/ANTEPROYECTO/2012 A 052.pdf 